\title{
Research on Investment Portfolio Mechanism in the Context of COVID-19
}

\author{
Linjing Yang ${ }^{1, *}$ \\ ${ }^{1}$ Enter Author Affiliation: School of Management, Tianjin University of Technology, Tianjin, 300380, China \\ *Corresponding author. Email: guanghua.ren@gecacademy.cn
}

\begin{abstract}
Portfolio theory provides an important conceptual foundation and a comprehensive set of analysis systems for portfolio creation and analysis, and it has a significant impact on modern investment management practice. The rationality of portfolio theory on decentralized investing is a critical theoretical foundation for the fund management industry's existence. Furthermore, Markowitz's notion of an "effective portfolio" redirected managers' focus away from individual stocks and toward constructing successful portfolios. Markowitz's portfolio theory has shown to be successful in reality regarding the optimal allocation of main asset types in a portfolio. This paper takes the investment portfolio as the theoretical entry point. In-depth research from concept, domestic and foreign research review, and application model (CAPM, Fama-French 5 factor model, and q-factor model). And this paper tried to explore the predictive power of asset pricing under the impact of the COVID-19 outbreak. On the one hand, the thorough analysis and summary of portfolio theory. On the other hand, it provides a theoretical basis for relevant portfolio practice.
\end{abstract}

Keywords: COVID-19, investment portfolio, Review

\section{INTRODUCTION}

Asset pricing is one of the most important indicators in financial research, widely used in the field of investment decision-making and corporate financial management. Since 2019, the global outbreak has had a huge impact on the market. The enterprise business decision, marketing, value production and resource control and other links have been greatly changed. The epidemic has affected the value of the capital assets of listed companies. The global economy has had a certain impact on asset pricing forecasting capabilities. However, the economic downturn during the Covid-19 got us interested in testing the predictability of asset pricing models.

\section{MAIN BODY}

\subsection{Investment Portfolio}

The portfolio is a collection of stocks, bonds, financial derivatives, etc., held by investors or financial institutions. The aim is to spread out the risks.

Two levels of the investment portfolio: The first level is the combination of assets, including equities, bonds and cash, how to move from one asset to the next; the second level is the combination of bonds and equities, the bond varieties of which are selected in the same asset level and the number of their respective weightings. Investors invest their funds in a certain proportion of securities or securities, respectively, and this decentralized investment method is the investment portfolio. Risk can be dispersed through the portfolio, which is one of the meanings of securities investment funds.

The US economist Markowitz initially proposed portfolio theory in 1952 [1]. The primary principle behind Macevitz portfolio theory is for investors to (1) pick the suitable assets for their portfolio; (2) analyze the projected returns and risks from those assets during their holding, and implement the strategy. (3) establishes an effective mix of alternative securities, and (4) ultimately determines the optimal portfolio of securities combined with specific investment objectives. The basic assumptions of Markowitz's portfolio theory are: (1) investors are reluctant to take risks and seek the maximum intended usefulness; (2) investors choose the portfolio according to the expected value and variance of yield; (3) All investors are in the same single investment period. Markowitz proposed identifying an effective portfolio based on expected earnings and variance $(\mathrm{E})$. 
Investment risk is calculated using the expected return $\mathrm{E}$ on securities, and risk is calculated using the variance of the return. Thus, the Markowitz optimization model is as follows where the portfolio's total return is expressed as the weighted average of each asset's expected return, and the risk of the combined assets is expressed as the variance or standard deviation of the return:

$$
\begin{aligned}
& \operatorname{Min} \delta^{2}\left(\mathrm{r}_{p}\right)=\sum \sum w_{i} w_{j} \operatorname{cov}\left(r_{i}, r_{j}\right) \\
& E\left(\mathrm{r}_{p}\right)=\sum w_{i} \mathrm{r}_{i}
\end{aligned}
$$

In the formula: $r_{p^{---P o r t f o l i o ~ e a r n i n g s ~}}$

$r_{u} / r_{j}$---Earnings of Class $\mathrm{i}$ and Class $\mathrm{j}$ assets

$w_{i} / w_{j}$---The asset $\mathrm{i}$ and asset $\mathrm{j}$ weights in the portfolio

$\delta^{2}\left(r_{p}\right)$---The overall risk of the portfolio is determined by the variation of the combined income.

$\operatorname{cov}\left(r_{i}, r_{j}\right)$---The relationship between the two assets' covariance.

The Markowitz model is a quadratic planning issue with an asset weight variable that can be addressed using the Lagrangian method in differential to find the best combination risk shovel $\delta^{2}\left(r_{p}\right)$ hourly ratio investment. In terms of economics, this means that investors decide on the desired yield in advance., and then determine the weight of each asset in the portfolio through $\mathrm{E}\left(\mathrm{r}_{\mathrm{p}}\right)=\sum \mathrm{w}_{\mathrm{i}} \mathrm{r}_{\mathrm{i}}$ to minimize the overall investment risk, so at different expected return levels, the corresponding solution minimizing the variance, which constitutes the minimum variance combination, namely the effective combination. The effective portfolio is defined as the curve formed by the yield expectation of an effective combination and the corresponding minimum variance. Based on their income goals and risk tolerance, investors choose the best portfolio plan at the front of the effective portfolio.

According to the Markowitz model, the realistic goal of portfolio design is to develop a portfolio with the maximum yield. Furthermore, the Markowitz model, which is extensively used in insurance portfolio management, provides an optimal procedure for developing the ideal target portfolio.

\subsection{A Review of Domestic Research}

In the beginning, the research of asset pricing in China mainly focuses on the factor model. According to the empirical analysis of Heda's analysis of the three-factor asset pricing model on representative stocks in China in 2015, the three-factor asset pricing model, especially the market excess yield factor, played a driving role in the decline of asset prices, thus making the empirical results of CAPM relatively good [2]. According to Fama-French's model, Xiong Mingda conducted an empirical test of the stock yield estimates of A-shares in the Shanghai and Shenzhen stock markets, using the data from the CSMAR database. It is concluded that the Fama-French three-factor model explains the yield of China's stock market well. In contrast, the scale factor and the book market value ratio factor can significantly improve the fitting effect of CAPM on the yield [3]. Hu Xuejie and Xie Mingyang investigated whether system risk is the only measure of asset risk, whether asset risk and return are positively related, whether there are other factors affecting stock pricing, whether asset risk and income are not positively related, and whether the CAPM model in the A stock market can effectively play the pricing effect [4]. Liu Yukun proposed that both the CAPM, Fama-French three factor, and the five factor model can effectively explain China's stock market yield. The three-factor model applies in both long-term and long-term models [5].

\subsection{A Review of Foreign Research}

In foreign research on asset pricing, there is an array of firm characteristics that are known to predict cross-sectional stock returns. Bernard and Thomas study the post-earnings-announcement drifts and find that the evidence cannot plausibly be reconciled with an argument built on risk mismeasurement but is consistent with a delayed price response [6]. The book-to-market relationship is larger than the size effect, according to Fama and French. However, the book-to-market ratio does not replace the size impact in regression using Fama Macbeth regression [7]. Jegadeesh and Titman show that relative strength strategies' profitability is not attributable to their systematic risk. The findings also show that relative strength earnings are not due to lead-lag effects caused by delayed stock price reactions to common causes [8]. According to Sloan, the relative magnitude of current earnings' cash and accrual components determines the extent to which current earnings performance persists into the future [9]. Dichev shows that higher returns do not compensate for the danger of bankruptcy. Therefore, a distress factor is unlikely to explain for size and book-to-market effects [10]. Titman et al. discover that firms that significantly increase their capital investments have negative returns after benchmark adjustment. Firms with greater investment discretion, i.e., bigger cash flows and lower debt ratios, have a stronger negative non-capital investment/return connection and only become significant when hostile takeovers are less common [11]. Daniel and Titman reveal that a stock's future return is strongly negatively correlated with "intangible" returns. A company's past performance is positively correlated 
with the stock's past return [12]. Fama and French present evidence that when controlling for the book-to-market equity ratio and expected investment, more profitable firms have higher expected returns than firms with higher book-to-market equity ratios [13]. Cooper et al. discover that the higher the asset growth rate, the higher the subsequent average annual risk-adjusted return. Total asset growth dominates other standard variables that predict future earnings in cross sections [14]. Xing provides evidence that portfolios of firms with low investment growth rates (IGRs) or low investment-to-capital ratios have significantly higher average returns than those with high IGRs or high investment-to-capital ratios in the cross-section, despite the value effects and the implications of standard Q-theory [15]. Novy-Marx states that profitability, as measured by total profits versus assets, shows that profitable companies have significantly higher returns than unprofitable ones. Profitable companies have longer-term cash flows and lower operating leverage [16].

\subsection{Model}

For studies of asset pricing, three models were selected here to perform the portfolio analysis.

\subsubsection{Capital Asset Pricing Model (CAPM)}

In 1964, American scholars Liam Sharpe, John Lintner, Jack Treynor, and Jan Mossin et al. based asset portfolio theory and capital market theory based on capital market pricing model, mainly study the relationship between the expected yield of assets and risk assets, and how equilibrium price is formed, is the pillar of modern financial market price theory, widely used in the field of investment banking.

The Capital Asset Pricing Model (CAPM) is a mathematical model whose primary goal is to determine how much remuneration investors should receive to compensate for a given level of risk. The development of capital and financial markets depends on the development of the CAPM model, which is widely used in micro and macro fields such as investment decision-making and theoretical analysis. The capital asset pricing model is based on the following assumptions: everyone invests in Markowitz's asset selection theory, and all expected returns, variance, and covariance estimates are identical, allowing investors to borrow freely. CAPM makes a very simple conclusion that only investing in high-stakes stocks gives investors higher returns.

\subsubsection{Fama-French 5 Factor Model}

In 1993, Fama and French introduced a three-factor model, claiming that market risk, market value risk, and book value ratio risk may explain excess stock returns.
They later observed that, in addition to the above-mentioned hazards, there are profit level risks and investment level risks that can result in excessive returns for individual stocks. Based on the three-factor model, two factors are added: profitability and investment model and proposed the five-factor model.

Five-factor model:

$$
\begin{aligned}
& R_{i t}-R_{F t}=a_{i}+b_{i}\left(R_{M t}-R_{F t}\right)+s_{i} S M B_{t}+ \\
& h_{i} H M L_{t}+r_{i} R M W_{t}+c_{i} C M A_{t}+e_{i t} \ldots \ldots \ldots . . .(3)
\end{aligned}
$$

Where is the expected portfolio return, $R_{f t}$ is the risk-free yield, $R_{m t}$ is the expected return for the market portfolio, and $\left(R_{m t}-R_{f t}\right)$ is the risk premium factor. Thus, SMB is a scale factor, HML is the book market value ratio factor, RMW is the difference in return on a high / low-profit equity portfolio. At the same time, CMA is the difference in return for low/high reinvestment ratios. These two components describe the profit level risk and the investment level risk, respectively (note that the investment level here is not the investment level of the secondary market but can be colloquially interpreted as the ability of enterprises to expand reproduction). The parameter estimation method is still multivariate linear regression, the same as the three-factor approach, and the a here is an unexplained excess gain in the five-factor model.

\subsubsection{Q-Factor Model}

The Q-factor model includes four risk factors. The first is the market factor, which encompasses both macroeconomic and overall market risk premiums. The second is the size factor that represents the market capitalization of a firm. The third factor is the investment factor. Investment means physical investment rather than a financial investment. The last factor is profitability. Earnings are the accounting profit ratio, which is equal to profit divided by book capital. Unlike the Fama-French five-factor model, which is just a summary and description of the market phenomenon, the $\mathrm{q}$ factor model has a more solid theoretical foundation. Kewei Hou, based on Tobin's Q theory, uses the neoclassical asset pricing method to derive the relationship between stock expected return and company profitability and investment scale through the stochastic discount factor model.

\section{CONCLUSION}

In this paper, we study the capital asset pricing model, including CAPM, Fama-French 5 factor model, Q-factor model, study the portfolio theory and review the relevant literature.

There are still some deficiencies in the current research, but it is still of great significance for the future: 
1. Although the existing literature has relatively rich research on portfolio theory, there is little research in the context of COVID-19, which needs to be further studied.

2. The existing literature on investment portfolios is all about matching different assets such as stocks, funds, and bonds. Still, there is less theoretical research on a company as a research object.

3. The existing literature for models, such as CAPM, Fama-5 factor model, Q-factor model, takes quantitative research methods as the main means, with less qualitative index research and logical description.

\section{REFERENCES}

[1] Markowitz H.M..Portfolio Selection [J] .Journal of Finance.1952 (7).

[2] Hoda.Empirical Analysis of Three-factor Asset Pricing Model [D].Huazhong University of Science and Technology, 2015.

[3] Xiong Mingda.Application of Fama-French three-factor model in Chinese Stock Market based on the empirical test of A-share market [J].Contemporary economy, 2015 (26): 130-131.

[4] Hu Xuejie, Xie Mingyang.Application of Capital Asset Pricing Model Based on China A-Share Market Data [J].Economic perspective, 2019 (05): 99-108.

[5] Liu Yukun.Applicability of Multifactorial Asset Pricing Model in Chinese Capital Market [D].Tianjin University, 2018.

[6] Bernard, Victor L., and Jacob K. Thomas, 1989, Post-Earnings-Announcement Drift: Delayed Price Response or Risk Premium?, Journal of Accounting Research 27, 1.

[7] Fama, Eugene F., and Kenneth R. French, 1992, The Cross-Section of Expected Stock Returns, The Journal of Finance 47, 427 - 465.

[8] Titman, 1993, Returns to Buying Winners and Selling Losers: Implications for Stock Market Efficiency, The Journal of Finance 34.

[9] Sloan, Richard G, 1996, Do stock prices fully reflect information in accruals and cash flows about future earnings?, Accounting review $289-315$.

[10] Dichev, Ilia D., 1998, Is the Risk of Bankruptcy a Systematic Risk?, The Journal of Finance 53, $1131-1147$.

[11] Titman, Sheridan, K C John Wei, and Feixue Xie, 2004, Capital Investments and Stock Returns, JOURNAL OF FINANCIAL AND

\section{QUANTITATIVE ANALYSIS 25.}

[12] Daniel, Kent, and Sheridan Titman, 2006, Market Reactions to Tangible and Intangible Information, The Journal of Finance 61, $1605-1643$.

[13] ]Fama, Eugene F, and Kenneth R French, 2006, Profitability, investment and average returns\$, Journal of Financial Economics 28.

[14] Cooper, Michael J., Huseyin Gulen, and Michael J. Schill, 2008, Asset Growth and the Cross-Section of Stock Returns, The Journal of Finance 63, $1609-1651$.

[15] Xing, Yuhang, 2008, Interpreting the Value Effect Through the Q-Theory: An Empirical Investigation, Review of Financial Studies 21, 1767 - 1795.

[16]Novy-Marx, Robert, 2013, The Other Side of Value: The Gross Profitability Premium, Journal of Financial Economics 73. 